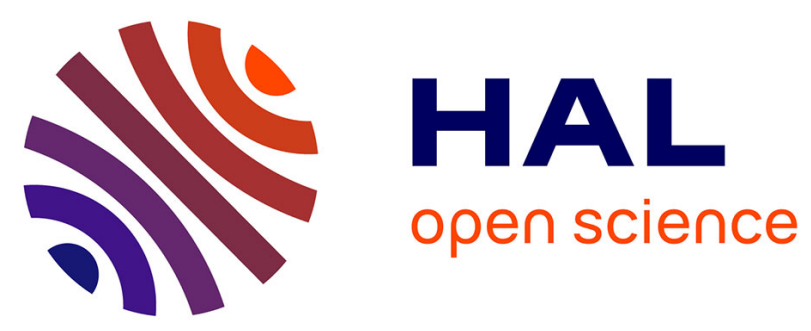

\title{
Shot noise of thermal plumes : Evidence of a boundary layer instability consistent with the onset of Kraichnan's Regime of convection
}

Frédéric Gauthier, Philippe-Emmanuel Roche

\section{- To cite this version:}

Frédéric Gauthier, Philippe-Emmanuel Roche. Shot noise of thermal plumes: Evidence of a boundary layer instability consistent with the onset of Kraichnan's Regime of convection. 12th EUROMECH

European Turbulence Conference, Sep 2009, Marburg, Germany. pp.521-524, 10.1007/978-3-64203085-7_125. hal-00430193

\section{HAL Id: hal-00430193 https://hal.science/hal-00430193}

Submitted on 9 Aug 2010

HAL is a multi-disciplinary open access archive for the deposit and dissemination of scientific research documents, whether they are published or not. The documents may come from teaching and research institutions in France or abroad, or from public or private research centers.
L'archive ouverte pluridisciplinaire HAL, est destinée au dépôt et à la diffusion de documents scientifiques de niveau recherche, publiés ou non, émanant des établissements d'enseignement et de recherche français ou étrangers, des laboratoires publics ou privés. 


\title{
Shot noise of thermal plumes : Evidence of a boundary layer instability consistent with the onset of Kraichnan's Regime of convection
}

\author{
F. Gauthier, and P.-E. Roche \\ Institut Néel, CNRS / UJF, BP166, F38042 Grenoble cedex 9, France \\ philippe.roche at grenoble.cnrs.fr
}

\section{Introduction and Motivation}

In 1997, an enhancement of heat transfer has been reported[1] in Rayleigh Bénard convection for Rayleigh numbers $R a \gtrsim 10^{12}$. This new regime -named "Ultimate Regime" in the original paper- was interpreted as the regime predicted by Kraichnan in 1962 [2] and which is characterized by the turbulence of the boundary layers of the convection cell. Although this interpretation has been indirectly supported by specific experimental tests, including the observation of the $N u \sim R a^{1 / 2}$ scaling predicted by Kraichnan for asymptotically high $R a$ [3], a direct evidence of fluctuations in the boundary layer was still missing. We report such an observation based on the measurement of the shot-noise induced by thermal plumes in the heating plate [4].

\section{Experimental set-up}

Probing fluctuations directly within the boundary layer itself raises instrumentation challenges due to its thinness, estimated as a tenth of a millimeter in cells such as the one used in [1]. To overcome this difficulty, we measured the low-frequency temperature fluctuations of the heating plate of the convection cell, which was Joule heated at a constant flux. As explained in [4], operation at cryogenic temperatures (around $6 \mathrm{~K}$ ) makes this measurement possible thanks to the thermal characteristic times of the fluid $(\mathrm{He})$ compared to those of the bottom plate material (OFHC annealed copper).

The cell (insert of Fig.1) is similar to the one used in [1]. The bottom plate temperature is monitored by 2 Ge thermistors (letter " $\mathrm{T}$ " on Fig.1), distant from each other by a plate's radius. At the frequency of interest (of order $10-100 \mathrm{mHz}$ ) they give consistent signal. The thermistors' time response was measured with the $3 \omega$ method. As displayed on Fig 1: their caracteristic frequency response is significantly larger than the frequencies of interest. 


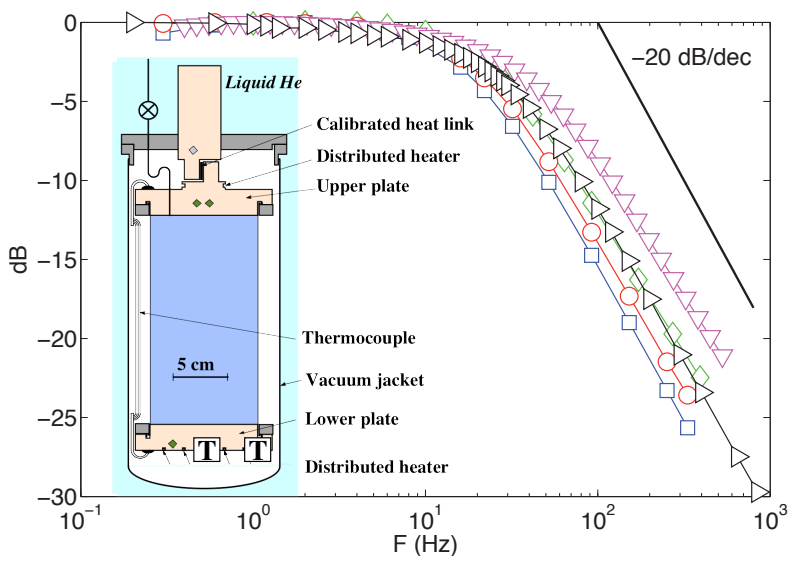

Fig. 1. Frequency response of the various thermistances of the set-up, measured in-situ by the $3 \omega$ technique. Insert : the cylindrical cryogenic convection cell. The letters "T" represents the thermometers used to measure temperature fluctuations.

\section{Results : a new signatures of the transition to the Ultimate Regime}

The insert of Fig. 2 shows temperature spectra for $5 \times 10^{10}<R a<6 \times 10^{13}$ and for Prandtl numbers of order $1(1.0 \leq \operatorname{Pr} \leq 2.8)$. At low frequency, spectral density plateaus $E_{\text {plateau }}$ can be fitted on data. The main figure shows the spectra rescaled by $E_{\text {plateau }}$ and by arbitrary frequencies $F_{c}$.

The spectral densities $E_{\text {plateau }}$ can be made dimensionless with the temperature difference across the cell $\Delta$, its height $h$ and the kinematic viscosity of the fluid $\nu: P^{\star}=E_{\text {plateau }} \nu /(h \Delta)^{2}$. Fig.3 (black symbols on the main plot) shows that $P^{\star}$ roughly scales like $R a^{-2 / 3}$ below $R a \simeq 2 \times 10^{12}$ but increases faster with $R a$ above. This threshold $R a$ is the same as the one for which the heat transfer across the cell improves significantly, compared to the "hard turbulence" regime present at lower $R a$. This is illustrated by the insert of Fig. 3 showing the Nusselt number $N u$ (compensated by $R a^{1 / 3}$ ) versus $R a$.

As illustrated by the histograms and the skewness of the temperature fluctuations (see Fig.4), the plate's fluctuations differ significantly from a gaussian distribution above $R a=2 \times 10^{12}$.

\section{Interpretation and Conclusion : a boundary layer instability}

Interestingly, for $R a<2 \times 10^{12}$, the low-frequency spectral density $P^{\star}$ of the plate temperature spectra coincides with the corresponding quantity in the bulk of the flow (measured previously in a similar experiment) but not above 


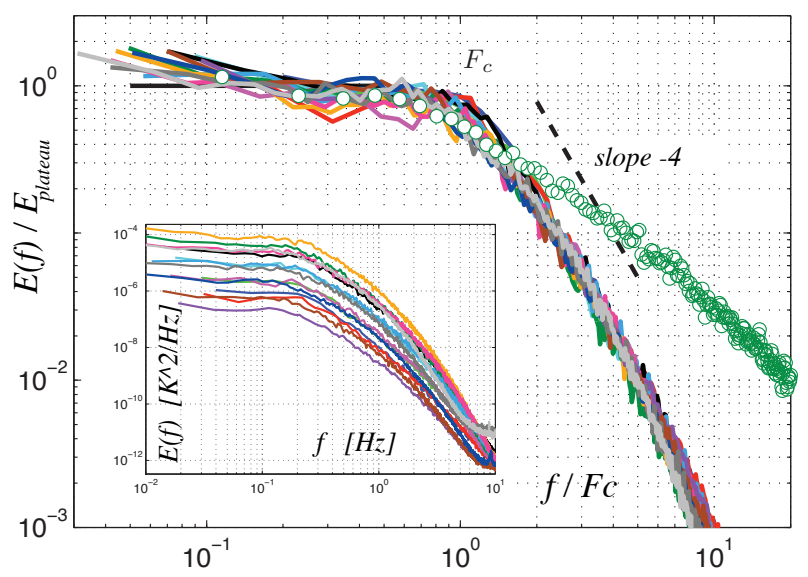

Fig. 2. Temperature power spectra of the bottom plate (continuous line) and of a local probe located in the core of the flow (circles) [1]. In the main plot, the spectra are rescaled by 2 ad-hoc parameters $E_{\text {plateau }}$ and $F_{c}$.

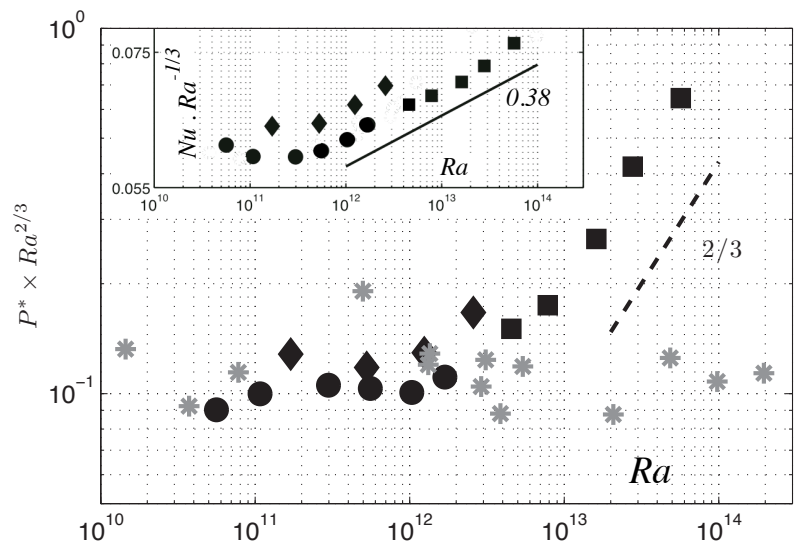

Fig. 3. Compensated spectral density of the low frequency temperature fluctuations of the bottom plate $(\bullet: \operatorname{Pr}=1.0, \diamond: \operatorname{Pr}=1.3, \boldsymbol{\square}: \operatorname{Pr}=2.8$. $)$ and of the bulk of the flow (*). Insert : Nusselt number $N u$, compensated by $R a^{1 / 3}$, versus $R a$ showing departure from a typical $R a^{1 / 3}$ scaling above $R a \simeq 10^{12}$.

$R a \sim 2 \times 10^{12}$ (see Fig.3). A straightforward interpretation, consistent with the time scales of the system [4], consists in assuming that the temperature of the plate follows the slow temperature fluctuations of the well-mixed core region of the flow, with an offset corresponding to the temperature drop across the thermal boundary layer. On average, this temperature drop is $\Delta / 2$. The present results indicate that the boundary layer becomes significantly "noisy" -compared to the residual fluctuations in the core of the flow- above a threshold of order $R a \sim 10^{12}$. This is consistent with the occurence of a instability in 


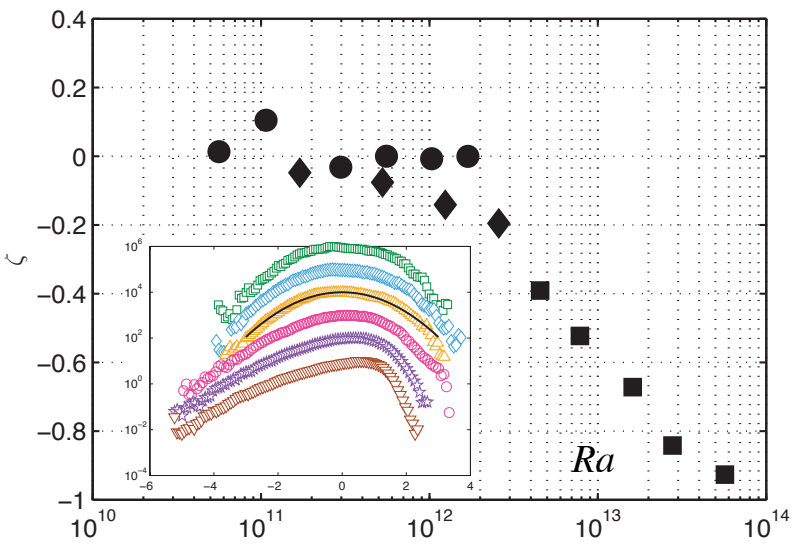

Fig. 4. Skewness of the temperature fluctuations of the plate versus $R a$ with same symbols as Fig.3. Insert : Histograms of the (centered) temperature fluctuations normalized by the standard deviation. $R a$ from top to bottom : $5.6 \times 10^{10}, 5.5 \times 10^{11}$, $1.7 \times 10^{12}, 4.5 \times 10^{12}, 1.6 \times 10^{13}$ and $5.7 \times 10^{13}$. The continuous line corresponds to a gaussian.

the thermal boundary layer, which would cause an increase of the fluctuations of the temperature drop across it.

In 1962, R. Kraichnan predicted that the thermal boundary layers in Rayleigh-Bénard convection should become unstable at high enough Rayleigh number, leading to an improved heat transfer. The increase in heat transfer $N u(R a)$ reported for $R a \sim 10^{12}-10^{13}$ in several experiments (since 1997) has been interpreted following Kraichnan's prediction. The present result confirms the occurrence of a boundary layer instability and is consistent with this interpretation.

Acknowledgements : We thank F. Chilla, Y. Gagne and B. Castaing for stimulating discussions.

\section{References}

1. Observation of the ultimate regime in Rayleigh-Bénard convection. Chavanne, X. et al., Phys. Rev. Lett. 79, 3648 (1997)

2. Turbulent thermal convection at arbitrary Prandtl numbers. Kraichnan, R., Phys. Fluids 5,1374 (1962)

3. Observation of the $1 / 2$ power law in Rayleigh-Bénard convection. Roche P.-E. et al., PRE, 63,045303(R) (2001)

4. Evidence of a boundary layer instability at very high Rayleigh number. Gauthier F. and Roche P.-E, EPL 83,24005 (2008) 